\title{
COMPORTAMENTO DE QUEDA DE FÊMEAS INGURGITADAS DO CARRAPATO Boophilus microplus. ${ }^{1}$
}

\author{
THE DROP-OFF BEHAVIOUR OF ENGORGED FEMALES OF THE \\ CATTLE TICK, Boophilus microplus
}

\author{
Paula Hocayen de Paula ${ }^{2}$ John Furlong $^{3}$
}

\section{RESUMO}

\begin{abstract}
A dinâmica de queda de fêmeas ingurgitadas do carrapato Boophilus microplus foi avaliada na Estação Experimental da Embrapa Gado de Leite, em Coronel Pacheco$M G$, Brasil. O objetivo foi avaliar as vantagens da modificação do horário de ordenha dos bovinos, considerando a higienização do pasto, em relação ao carrapato. $O$ experimento constou de uma fase de verão/outono e uma de inverno, para testar diferenças no ritmo de queda dos carrapatos entre as duas estações. Os resultados mostraram diferenças significativas entre as fases. No verão/outono, as fêmeas ingurgitadas apresentaram maior porcentagem de queda entre 7 e 10 horas $(35,3 \%)$ e no inverno entre 6 e 9 horas $(19,69 \%)$ e entre 14 e 17 horas $(21,79 \%)$. A porcentagem de queda de fêmeas ingurgitadas no periodo foi de 35,15\% para o sistema de ordenha de 5-8h e 13$16 \mathrm{~h}$ e de 45,48\% para o sistema de ordenha de 8-11h e 16-19h, durante os meses de verão/outono. Nos meses de inverno, o porcentual de queda foi de $40,51 \%$ e de $32,71 \%$ para os dois horários de ordenha respectivamente. Considerando o tempo que os animais permanecem estabulados para a suplementação no cocho durante o periodo entre as ordenhas na época seca do ano na região (maio a setembro), a porcentagem de queda de fêmeas ingurgitadas foi de 55,83\% para o sistema de ordenha de 5 a $16 \mathrm{~h}$ e de 52,36\% para o sistema de ordenha de 8 a $19 \mathrm{~h}$.
\end{abstract}

Palavras-chave: comportamento de queda, fêmea ingurgitada, Boophilus microplus, bovinos.

\section{SUMMARY}

A description of the drop-off behaviour of engorged females of the tick Boophilus microplus was carried out as a result of an experiment at the Experimental Station, Embrapa Gado de Leite, Coronel Pacheco, MG, Brazil. Its objective was to evaluate any repercussions of changing the time of milking of cattle in terms of reduced recontamination of the pastures with the tick. Such possible changes in this daily cattle management routine have recently become a reality since the advent of refrigerated on-farm storage of the milk and non-daily collection by tanker truck. The field experiment consisted of a phase in summer, with a longer photoperiod, and in winter, with a shorter photoperiod. Twelve weekly experimental repetitions, of 24 hours duration, were carried out in each of these seasons. For each repetition, eight non-lactating, 7/8 Holstein-Friesian $x$ Zebu cows, naturally infested with B. microplus and maintained on pastures, were removed to an experimental area on the day in which the observations were to be made and maintained in individual stalls. At each hour, over 24 hours, all fully engorged ticks that had dropped off naturally from the cattle were collected from the stalls. The results showed a significant difference in the rhythm of their drop-off in the summer compared to winter. In the summer the greater proportion of ticks dropped off between 07 and $10(35.3 \%)$ with a maximum at 09. In winter, there were two daily periods of greater drop-off of ticks, the first between 06 and $09(19.69 \%)$ with a maximum at 06, and the second between 14 and $17(21.79 \%)$ with a maximum at 15 . The percentage of ticks dropping off during the traditional milking time (05-08 and 1316) would have been $35.15 \%$, while those falling during an alternative sytem under consideration for Central Brazil (08-11 and 16-19) would be 45.48\%, during the summer. During the winter, the proportion of ticks falling from the cattle is $40.51 \%$ and $32.71 \%$ for the two times of milking, respectively. Considering the time that the animals remain in stalls for feed supplement during the period between milkings during the dry season (May to September), the proportion of ticks falling would be $55.83 \%$ for the traditional system (05-16) and $52.36 \%$ for the milking period under consideration (08-19).

Key words: Boophilus microplus, drop-off behaviour, engorged female, dairy cattle.

\footnotetext{
${ }^{1}$ Parte da dissertação de mestrado apresentada pelo primeiro autor à Universidade Federal de Juiz de Fora (UFJF), Juiz de Fora, MG.

${ }^{2}$ Biólogo, Mestre.

${ }^{3}$ Médico Veterinário, Doutor, Pesquisador da Embrapa Gado de Leite, Rua Eugênio do Nascimento 610, 36038-330, Juiz de Fora, MG.

E-mail: john@enpgl.embrapa.br. Autor para correspondência.
} 


\section{INTRODUÇÃO}

Por mais de um século, o controle químico pelo uso de acaricidas tem sido a principal forma de controle dos carrapatos. No entanto, o uso indiscriminado dos carrapaticidas tem determinado um grave quadro de resistência, de ordem genética, dos carrapatos em relação às drogas (FURLONG, 1993). A resistência tem se desenvolvido cada vez mais rápido, de tal forma que a vida útil dos produtos foi reduzida para quatro a cinco anos em média (HONER \& GOMES, 1990).

Os estudos biológico, comportamental e ecológico do carrapato têm tido grande ênfase ultimamente, com o objetivo de se desenvolver formas de controle baseadas no manejo do animal, de forma a reduzir o uso das drogas, na tentativa de, ao menos, minimizar o problema. Este trabalho se concentrou no estudo do comportamento de desprendimento e queda das fêmeas ingurgitadas do B. microplus, na passagem da fase de vida parasitária para a não-parasitária.

O comportamento de queda destas fêmeas ingurgitadas não ocorre ao acaso, já que espécies diferentes de carrapatos apresentam picos de queda em determinados horários do dia (CORDOVÉS, 1996). Para o caso do B. microplus no entanto, poucos autores tratam deste assunto. HITCHCOCK (1955) observou em experimento na Austrália com animais estabulados, que o pico de queda das fêmeas ingurgitadas $\boldsymbol{B}$. microplus ocorreu das 6 às 10 horas da manhã, o que sugere que o fato pode estar relacionado ao ritmo do hospedeiro, que se alimentava por volta das 8 horas da manhã, o que provavelmente provocaria "distúrbios" nos carrapatos.

SONENSHINE (1993) citou que o ritmo de queda das fêmeas ingurgitadas pode ser influenciado pelo ritmo do hospedeiro, já que em algumas espécies de carrapatos, a queda acontece quando o hospedeiro está mais ativo e em outras espécies quando o hospedeiro apresenta baixa atividade. GEORGE (1971) descreveu que o ritmo de queda do carrapato pode ser influenciado pelo ritmo do hospedeiro e confirmou este fato em experimento no qual mostrou que, em animais alimentados em horários diferentes, o ritmo de queda dos carrapatos também se alterava (GEORGE et al., 1998). WHARTON e UTECH (1970), trabalhando com animais estabulados e a pasto, no verão e inverno na Austrália, também observaram o pico de queda das fêmeas ingurgitadas às 9 horas da manhã para ambas as estações. No entanto, encontraram outros fatores que diferiam consideravelmente entre as duas estações, o que levou os autores a afirmarem que o ritmo de queda poderia ser influenciado pelo fotoperíodo, fato também observado e confirmado por KITAOKA (1962) e citado por SONENSHINE (1993). NÚÑEZ et al. (1972) também citaram que o pico de queda das fêmeas ingurgitadas de B. microplus ocorreu pela manhã, mas não descreveram nenhuma possível explicação para o fato.

Estes ritmos de queda das fêmeas ingurgitadas talvez possam ser usados em um sentido prático: reter os animais nos currais durante as primeiras horas do dia, horário que grande parte dos carrapatos irá desprender-se. Essa poderia ser uma forma efetiva de controle, ligada apenas ao manejo do gado, resultando em diminuição considerável do número de carrapatos na pastagem, além da diminuição da pressão de seleção de resistência das populações de carrapato aos carrapaticidas. Assim, o intervalo de tempo em que os animais permanecem estabulados para a ordenha é muito importante para este processo. Este trabalho foi, portanto, desenvolvido com o objetivo de se conhecer o comportamento de desprendimento e queda das fêmeas ingurgitadas do carrapato $\boldsymbol{B}$. microplus, em duas épocas do ano, no intuito de contribuir para o estabelecimento de medidas de controle dos carrapatos ligadas ao manejo dos animais.

\section{MATERIAL E MÉTODOS}

O experimento foi realizado na Estação Experimental da Embrapa Gado de Leite, situada na cidade de Coronel Pacheco, MG, $\left(21^{\circ} 45^{\prime} 35^{\prime}\right.$ 'S e $\left.43^{\circ} 15^{\prime} \mathrm{W}\right)$. O clima da região é do tipo $\mathrm{Cwb}$, com altitude de $435 \mathrm{~m}$, médias das temperaturas variando entre $27,9^{\circ} \mathrm{C}$ (máxima) e $15,3^{\circ} \mathrm{C}$ (mínima), e precipitação de 1581,4mm (BRASIL, 1992). Foram usadas 8 vacas secas, de grau de sangue $7 / 8$ Holandês x Zebu, $84 \%$ de sangue Bos taurus, naturalmente infestadas com o carrapato $\boldsymbol{B}$. microplus, mantidas em regime de pasto e identificadas por brincos. Na Estação Experimental, os animais usados nos experimentos ficaram em pastos e foram conduzidos à área experimental uma vez por semana, onde foram confinados em baias individuais e as coletas do experimento eram feitas.

$\mathrm{O}$ experimento compreendeu uma fase de verão/outono e outra de inverno, sendo que as observações de verão/outono se deram no meses de fevereiro, março e abril de 1999 e as observações de inverno, nos meses de maio, junho, julho e agosto de 1999. Foram efetuadas doze observações de vinte e quatro horas, uma a cada semana, nos meses de verão/outono e doze observações nos meses de 
inverno. Nestas vinte e quatro horas, foram coletadas, de hora em hora, no chão de cada baia, as fêmeas ingurgitadas do carrapato que haviam se desprendido naturalmente do animal. As observações noturnas foram feitas com o auxílio de lanternas, de forma que os animais permanecessem no escuro, já que a luz poderia influenciar os resultados. O número de fêmeas ingurgitadas coletadas em cada baia individualmente era registrado e analisado estatisticamente pelo SAS, usando-se as correlações de Pearson e Spearman.

\section{RESULTADOS}

Em relação ao estudo do comportamento de queda de fêmeas ingurgitadas do carrapato $\boldsymbol{B}$. microplus, os resultados mostraram diferenças significativas entre as coletas de verão/outono e inverno. No verão/outono, as fêmeas ingurgitadas apresentaram uma maior porcentagem de queda nas primeiras horas da manhã, e continuavam a cair durante todo o dia, inclusive à noite, porém em porcentagens inferiores. Houve maior porcentagem de queda nos horários das 7 às 10 horas $(35,3 \%)$, sendo que o pique ocorreu às 9 horas com 12,96\% do total de queda. Os horários de menor porcentagem de queda foram das 12 às 15 horas $(9,87 \%)$, sendo que a menor porcentagem foi às 14 horas com $1,22 \%$ do total.

No inverno, as fêmeas ingurgitadas do carrapato B. microplus apresentaram dois piques de queda durante o dia: um entre 6 e 9h $(19,69 \%)$ com maior porcentagem às 6 horas $(5,96 \%) \mathrm{e}$ outro maior entre 14 e $17 \mathrm{~h} \quad(21,79 \%)$ com maior porcentagem às 15 horas $(7,17 \%)$.

Em relação à possibilidade de atrasar o horário da ordenha, de forma que os animais estivessem a campo nos horários de maior intensidade de pastejo, os resultados possibilitaram a mensuração da porcentagem de carrapatos que se desprendem do animal na hora da ordenha. Na tabela 1, são apresentados os resultados para os sistemas de ordenha atual (de 5-8h e de 13-16h) e para o sistema em estudo, onde a ordenha da manhã seria entre 8 e 11 horas e a da tarde entre 16 e 19 horas.

No caso dos sistemas de suplementação no cocho para os animais, na época seca do ano, normalmente de maio a setembro, onde os animais permanecem estabulados entre as duas ordenhas, o porcentual de queda de fêmeas ingurgitadas de $\boldsymbol{B}$. microplus desprendidas neste intervalo é de 55,83\% para o sistema de estabulação 5 às 16 h e de $52,36 \%$ para o sistema de estabulação de 8 às $19 \mathrm{~h}$.

\section{DISCUSSÃO}

A maior porcentagem de queda de fêmeas ingurgitadas do carrapato $\boldsymbol{B}$. microplus ocorrida entre 7 e 10 horas com pique de queda às 9 horas para as repetições de verão/outono, coincide com os resultados encontrados por HITCHCOCK (1955), onde a maior quantidade de fêmeas ingurgitadas de B. microplus se desprendeu entre 6 e 10 horas. WHARTON \& UTECH (1970) descreveram resultados semelhantes, apontando maior ritmo de queda nas primeiras horas da manhã, com pico às 9 horas para os resultados de verão e às 9:30 para o inverno. NÚÑEZ et $\boldsymbol{a l}$. (1972) também encontraram maior freqüência de queda pela manhã, trabalhando nos meses de verão (janeiro e fevereiro) na Argentina. Este comportamento também é descrito por KITAOKA (1962), sendo que estes autores trabalharam com B. microplus.

Nenhuma bibliografia porém, mostra resultados que coincidem exatamente com aqueles obtidos nas repetições de inverno, onde foi encontrado um pique de queda de fêmeas ingurgitadas entre 6 e 9 horas e outro entre 14 e 17 horas. Apenas GEORGE et al. (1998), trabalhando com B. annulatus em bovinos no Texas, USA, encontraram maior porcentagem de queda na parte da tarde, porém os resultados foram semelhantes para as três repetições realizadas: uma, no inverno, com fotoperíodo de $10 \mathrm{~h} 37^{\prime}$, com pique entre13 e 15 horas; outra, no verão, com fotoperíodo de $12 \mathrm{~h} 27$ ' horas com pico de queda entre 12 e 16 horas, e uma última, no outono, com fotoperíodo médio de $12 \mathrm{~h} 22$ ' e com maior freqüência de queda entre 14-18 horas $(29,5 \%)$, o que difere dos resultados do presente trabalho, já que nas repetições de verão/outono o pique de queda ocorreu pela manhã. Os autores citados não têm certeza dos fatores que determinam o ritmo de queda de fêmeas ingurgitadas. HITCHCOCK (1955) acredita que este comportamento pode ser influenciado pela atividade do hospedeiro, uma vez que, no experimento realizado por ele, os animais foram alimentados por volta das 8 horas. Esta forma de manejo poderia causar distúrbios na população de carrapatos e determinar a queda das fêmeas nas primeiras horas da manhã. No presente trabalho, os animais foram alimentados entre 9 e 10 horas, durante o dia em que se encontravam estabulados, o que poderia confirmar esta proposição levando-se em consideração os resultados de verão/outono e inverno, com pique de queda dos carrapatos pela manhã.

O fotoperíodo parece ser $\mathrm{o}$ fator predominante para determinar o ritmo de queda das 
Tabela 1 - Porcentagem de fêmeas ingurgitadas de Boophilus microplus desprendidas de vacas durante o período de estabulação para a ordenha no horário do sistema atual e no sistema em estudo para a Região do Brasil-Central. Coronel Pacheco, MG, 1999.

\begin{tabular}{lcclcc}
\hline \multicolumn{2}{c}{ ORDENHA NO SISTEMA ATUAL } & \multicolumn{2}{c}{ ORDENHA EM ESTUDO PARA O BRASIL-CENTRAL } \\
ORDENHA & VERÃO & INVERNO & ORDENHA & VERÃO & INVERNO \\
\hline MANHÃ & & & MANHÃ & & \\
$5-8$ horas & $28,40 \%$ & $19,00 \%$ & $8-11$ horas & $32,43 \%$ & $15,51 \%$ \\
TARDE & & & TARDE & & $17,20 \%$ \\
$\begin{array}{l}13-16 \text { horas } \\
\text { TOTAL }\end{array}$ & $6,75 \%$ & $21,52 \%$ & $16-19$ horas & $13,15 \%$ & $32,71 \%$ \\
\hline
\end{tabular}

fêmeas ingurgitadas, tendo em vista as diferenças encontradas entre as repetições de verão/outono e inverno no trabalho realizado por WHARTON \& UTECH, (1970). Esta suposição poderia justificar as diferenças significativas encontradas no presente trabalho, entre os resultados de verão/outono e inverno. O ritmo diurno de queda dos carrapatos pode ser dependente primeiramente do final do ingurgitamento e secundariamente de algumas condições físicas externas, estado fisiológico e movimento do hospedeiro. O principal fator externo seria a luz, já que em muitas observações feitas por KITAOKA (1962), os carrapatos caíram instantaneamente ao amanhecer. Semelhante resultado foi encontrado no presente estudo, tanto nas repetições de inverno (pique de queda às 6 horas) como nas repetições de verão/outono (pique de queda também às 5 horas, além do pique das 9 horas) com horário de amanhecer aproximadamente às 6:30 e 5:30 respectivamente no inverno e no verão/outono.

A atividade dos bovinos varia de acordo com a estação do ano, raça e condições da pastagem, o que poderia influenciar o horário de queda, já que seria mais vantajoso para o carrapato cair nos locais de pastagem, onde fica protegido na vegetação, do que em bebedouros ou lugares onde o gado se reúne para descansar e ruminar (malhadouro) (GEORGE et al., 1998). Há uma relação entre o comportamento de pastejo e o grau de tolerância ao calor exibido pelos bovinos (FINDLAY, 1956). Vacas holandesas em regime de pasto alteram o padrão de pastejo tentando evitar as horas mais quentes do dia (PIRES et. al., 2000) Os resultados do presente trabalho mostram que os carrapatos apresentam um pique de queda à tarde, entre 14 e 17 horas para as repetições de inverno, sendo que o mesmo não ocorre no verão/outono quando a "menor" porcentagem de queda ocorre entre 12 e 15 horas.

Em se considerando estes resultados e as afirmações dos autores supracitados, pode-se inferir que, no inverno, os animais apresentariam maior intensidade de pastejo à tarde, já que as temperaturas são mais amenas, em se tratando da região de BrasilCentral, e que, desta forma, os carrapatos poderiam ter se adaptado a esta realidade. $\mathrm{O}$ mesmo não ocorreria no verão/outono, quando as médias de temperatura são mais altas, fazendo com que os animais procurem os bebedouros, malhadores ou sombra, confirmando a sugestão de GEORGE et al. (1998). Estes autores sugerem ainda que o ritmo de queda pode ser influenciado pelo estado nutricional e fisiológico do hospedeiro já que em outro experimento foram separados 3 grupos de animais e cada um deles alimentado em horários diferentes. Os resultados mostraram diferenças entre o ritmo de queda dos carrapatos dos grupos. No presente estudo, esta suposição não justificaria as diferenças entre o ritmo de queda entre verão/outono e inverno, uma vez que os animais foram alimentados sempre no mesmo horário em ambas as estações.

É importante frisar que o presente estudo é o primeiro a ser realizado no Brasil e América Latina sobre o ritmo de queda das fêmeas ingurgitadas do carrapato B. microplus. Os trabalhos existentes foram realizados em climas, pastagens e cruzamentos de bovinos diferentes dos encontrados no Brasil, o que poderia justificar as diferenças entre os resultados.

Em se tratando da sugestão de atrasar o horário da ordenha por causa dos fatores já citados em relação à preferência dos bovinos de leite quanto à hora de pastejo, e considerando os resultados de ritmo de queda dos carrapatos, no verão/outono, haveria um acréscimo de $10,43 \%$ de fêmeas ingurgitadas desprendidas no intervalo das ordenhas e um decréscimo de $7,85 \%$ para o mesmo intervalo no inverno. Em relação aos sistemas semi-intensivos nos quais os animais são alimentados no cocho, ficando livres para o acesso ao pasto depois de saciados, ou no manejo comum de suplementação dos animais no cocho entre as ordenhas na época seca do ano, os horários de cada atividade poderiam ser coordenados com o horário de queda das fêmeas ingurgitadas do carrapato.

É importante salientar que novos trabalhos deverão ser realizados a fim de se estudar o ritmo de queda de fêmeas ingurgitadas do 
carrapato $\boldsymbol{B}$. microplus em relação às mudanças do horário de alimentação e horário da ordenha dos animais, visto que segundo GEORGE et al. (1998), os carrapatos seriam capazes de adaptar o ritmo de desprendimento à rotina do hospedeiro. De posse das informações obtidas neste trabalho, pesquisadores e produtores terão a oportunidade de desenvolver outras formas de manejo, capazes de aumentar a eficiência dos sistemas atuais de produção na região do Brasil-Central em função de preferências alimentares dos bovinos e presumir as vantagens ou desvantagens em relação à infestação do rebanho pelos carrapatos, higienização da pastagem e utilização de acaricidas.

\section{CONCLUSÕES}

O ritmo de queda de fêmeas ingurgitadas do carrapato Boophilus microplus apresenta diferenças significativas entre verão/outono e inverno e parece estar adaptado ao comportamento de pastejo dos bovinos. Ainda não é possível sugerir a troca do horário da ordenha apenas como forma de controle dos carrapatos.

\section{REFERÊNCIAS BIBLIOGRÁFICAS}

BRASIL. Normais climatológicas (1961-1990). Brasília : Ministério da Agricultura e Reforma Agrária. Secretaria Nacional de Irrigação, Departamento Nacional de Meteorologia, 1992. 84p.

CORDOVÉS, C.O. Carrapato: controle ou erradicação. Alegrete : Gralha, 1996. $130 \mathrm{p}$

FINDLAY, J.D. The effects of temperature, humidity, air movement and solar radiation on behavior and physiology of cattle and other farm animals. Dairy Research Bulletin, v.9, p.178. 1956.

FURLONG, J. Controle do carrapato dos bovinos na região sudeste do Brasil. Cadernos da Escola de veterinária UFMG. Belo Horizonte : CENEX, 1993. v.8, p.49-61.
GEORGE, J.E. Drop-off rhythms of engorged rabbit ticks, Haemaphys leporispalustris (Packard, 1896) (Acari: Ixodidae). Journal of Medical Entomology, v.8, n.5, p.461470, 1971

GEORGE J.E., POUND, J.M., DAVEY, R.B. Observations of the rhythm of detachment of engorged female Boophilus annulatus (Acari: Ixodidae) from cattle. Entomological Society of America, v.35, n.4, p.479-482, 1998.

HITCHCOCK, L.F. Studies on the parasitic stages of the cattle tick, Boophilus microplus (CANESTRINI) (ACARINA:IXODIDAE). Australian Journal of Zoology, v.3, n.2, p.145-155, 1955.

HONER, M.R., A. GOMES. O manejo integrado de mosca dos chifres, berne e carrapato em gado de corte. Campo Grande : Embrapa Gado de Corte, 1990. 60 p. (Circular Técnica, 22).

KITAOKA, S. Physiological and ecological studies on some ticks.VIII. Diurnal and nocturnal changes in feeding activity during the blood-sucking process of Haemaphysalis bispinosa. National Institut Animal Health Quarterline, v.2, n.2, p.106-111, 1962.

NÚÑEZ, D.J.L., M.E. PUGLIESE, R.P. HAYES. Boophilus microplus Can. Estudio sobre los estadios parasitarios del ciclo biológico. Revista de Medicina Veterinaria, v.58, n.1, p.19-35, 1972.

PIRES, M.F.A., ALVIM, M.J., VILELA, D., et al. Comportamento de vacas holandesas em sistema de pastagens. In: REUNION LATINOAMERICANA DE PRODUCCION ANIMAL, 16, 2000 e CONGRESSO URUGUAYO DE PRODUCCION ANIMAL, 3., 2000, Montevideo. Anais... Montevideo : Latinoamerica Productora de Alimentos Naturales de Origen Animal, 2000. p.1. (CD Rom).

SONENSHINE, D.E. Biology of ticks. New York : Oxford University, 1993. v.2, 465p.

WHARTON, R.H., K.B.W. UTECH. The relation between engorgement and dropping of Boophilus microplus (Canestrini) (Ixodidae) to the assessment of tick numbers on cattle. Journal of Australian Entomology Society, v.9, p.171-182, 1970. 